\title{
Measuring Material Deprivation with EU-SILC: Lessons from the Irish Survey
}

Christopher T. Whelan and Bertrand Maitre

\author{
Economic and Social Research Institute, \\ 4 Burlington Road \\ Dublin 4 \\ Ireland
}

Tel: +35316671525

Fax: +3531668 6231

Email: Chris.Whelan@esri.ie 


\section{Abstract}

In this paper we consider the consequences for measurement of material deprivation, consistent poverty and economic vulnerability of the shift from the ECHP data set to the EU-SILC instrument. Despite the restricted number of deprivation items available in EU-SILC, we show that there is a substantial overlap between such measures when they are estimated using EU-wide and Irish specific indicators. By placing the EUwide measures in the context of the full range of Irish indicators, we demonstrate that they allow us to identify clusters of individuals sharply differentiated in terms of their multidimensional deprivation profiles. They also provide an understanding of the socio-economic factors associated with such differentiation that departs in only modest respects from that derived from the more comprehensive set of Irish specific indicators.

Key words: income poverty, material deprivation, multidimensionality, consistent poverty, economic strain, economic stress. 


\section{Introduction}

During the period 1994-2001 the European Community Household Panel (ECHP) was the primary source for the analysis of poverty and social exclusion in the European Union. The range of data available in the ECHP meant that it was possible to go beyond documenting income poverty levels and adopt a multidimensional perspective on social exclusion. In particular, the availability of detailed information relating to material deprivation encouraged a range of work exploring the relationship between income poverty and deprivation, measurement of economic vulnerability and multidimensional deprivation $^{1}$

With the termination of the ECHP the European Union Statistics on Income and Living Conditions (EU-SILC) instrument is potentially the primary source for such analysis. It is from this source that the common statistical indicators endorsed by the Laeken Council in 2001, and later refined by the Social Protection Committee to serve as an essential element in the Open Method of Coordination will be drawn. EU-SILC is organised under a Framework Regulation of the European Parliament and the Council. However, it was launched in 2003 on the basis of a 'gentleman's agreement' in six Member States as well as in Norway. The starting date for the EU-15 (with the exception of Germany, Netherlands and the UK who had derogations until 2005) as well as for Estonia, Norway and Iceland was 2004. The remaining New Member states started in 2005. The first set of micro data and cross-sectional indicators from

\footnotetext{
${ }^{1}$ See Muffels and Fouarge (2004), Whelan et al (2001, 2004), Tsakloglou and Papadopoulous (2002)
} 
EU-SILC covering all EU25 Member States is due in December 2006. ${ }^{2}$ In the transition period Eurostat has launched a collection of indicators derived from national sources including the data collected by the six countries at the forefront of EU-SILC data collection. ${ }^{3}$

EU-SILC differs from ECHP in a number of important respects. Of particular interest for our present purposes is the fact that the range of life-style deprivation indicators available in the former is substantially more restricted. Thus, the question arises as to what extent it will be possible to emulate the range of research conducted in relation to such outcomes with EU-SILC data. Material deprivation can be defined as involving the enforced lack of of items depicting relating to living conditions, such as ability to afford basic requirements, possession of consumer durables, housing conditions etc. ${ }^{4}$ As part of a growing emphasis on the multidimensionality of poverty and social exclusion, the value of such deprivation indicators has increasingly been recognized. The Eurostat (2005b: 2) report constitutes the first published effort employing EU-SILC data to address such issues. That paper notes that the development and use of material deprivation indicators is currently being discussed by the Social Protection Committee with a view to refining and consolidating the original list of the Laeken common indicators relating to poverty and social exclusion. In anticipation of the availability of the harmonized micro data set for the 25 Member States collected under the EU-SILC instrument, Eurostat (2005b) investigated the construction of material indicators using both ECHP and EU-SILC data sources but focusing solely on the items available in both sources. The subsequent analysis is based on ten items that are found to form three clusters that are labeled as "economic

\footnotetext{
${ }^{2}$ See Eurostat (2005a) for a more detailed discussion

${ }^{3}$ See Eurostat (2005 a \& b).

${ }^{4}$ See Nolan and Whelan (1996) and Eurostat (2005:2).
} 
strain", “durables" and "housing”, although for much of the analysis the first two clusters are merged. Using these measures Eurostat (2005b) presents a range of interesting results relating to deprivation levels and consistent poverty with the latter being defined as incorporating enforced material deprivation and low income.

A major concern relating to the Eurostat analysis relates to the fact that the number of items involved is extremely small. This is reflected in the fact that, using the first complete wave of the Irish data collected in 2004, the Cronbach's alpha reliability level for the four item economic strain index is 0.57 while that for the seven item index combining economic strain and consumer durables is 0.65 . These values are the low side for indices that are intended to play a central role in the analysis of material deprivation and consistent poverty. In this paper we take advantage of the fact that the Irish component of EU-SILC contains a much broader range of material deprivation indicators than the set that is common to the EU25,

In the Irish case the 2004 wave of the EU-SILC survey has been used to construct indices of consistent poverty and what we refer to as 'economic vulnerability' by selecting their constituent indicators, from a broad range of potential items, on a theoretically informed basis and in the light of the findings from previous research. It has also been possible to undertake a process of construct validation involving the use of both deprivation indicators not forming part of these indices and a number of measures of subjective economic pressures that we have deliberately excluded. ${ }^{5}$ The Irish measures can provide a context in which we can evaluate measures based on the indicators available on an EU wide basis.

\footnotetext{
${ }^{5}$ See Whelan et al (2006), Whelan and Maître (2006).
} 
The strategy we pursue is similar to that employed by McKay and Collard (2003) in developing deprivation indicators for the UK Family Resources Survey; in that we seek to demonstrate that it is not necessary to have a large suite of questions if a smaller set exhibit comparable discriminatory power. On the same basis, it may be possible to incorporate items in our indices, such as reports of experience of economic pressures, that otherwise we might reject on the basis that they are more appropriately used as reference points against which we should validate our measures.

In the analysis that follows we will make use of 46 indicators that are available in the Irish component of EU-SILC and a sub-set of 21 items that are available crossnationally. ${ }^{6}$ Using the latter, we shall proceed to examine the dimensionality of deprivation and levels of 'consistent poverty' and 'economic vulnerability'. At each stage we will consider how our conclusions compare to those arising from analysis based on the more comprehensive set of Irish items.

In nesting our analysis of the set of common EU-SILC items in the context of a parallel set of analyses based on the more comprehensive set of Irish indicators, we distinguish two different aspects of measurement: identifying the poor/counting the number poor versus capturing what it means to be poor. We shall seek to illustrate that a restricted set of indicators may be sufficient to identify those who experience more broadly based deprivation. The degree of multidimensionality required in identifying the poor/excluded is an empirical matter. It is not something one can

\footnotetext{
${ }^{6}$ We do not make use of the item relating to enforced absence of a colour television because as is clear form Eurostat (2005b) within the EU15 hardly anyone reports deprivation in relation to this item. We also exclude the item related to being able to save because of difficulties involved in interpreting it.
} 
simply read off from the multidimensional nature of the concepts themselves. ${ }^{7}$ By placing analyses based on the more restricted group of items in the context of findings arising from the broader set, we can test the extent to which indices based on the former succeed in capturing more widespread patterns of differentiation.

\section{Data and Measures}

In Ireland the information required under this EU-SILC framework is being obtained via a new survey to be conducted by the Central Statistics Office (CSO) each year. The first full wave of the survey was conducted in 2004 (CSO 2005). The EU-SILC survey is a voluntary survey of private households. In 2004 the total completed sample size was 5,477 households and 14,272 individuals. A two-stage sample design with eight population density stratum groups with random selection of sample and substitute households within blocks and the application of appropriate weight was employed (CSO, 2005).

The core aim of EU-SILC is to provide a basis for monitoring living standards, poverty and social exclusion. Income is defined as equivalised household disposable income with the equivalence scale employed attributing a weight of 1 to the first adult, 0.66 to each subsequent adult (aged 14+ living in the household) and 0.33 to each child aged less than 14. The at-risk-of poverty-rate is the share of persons with an equivalised income below a given percentage of the national median income. The set of deprivation questions posed covered a wide spectrum of items ranging from possession of consumer durables, quality of housing and neighbourhood environment to health status. Our analysis makes use of forty-two such indicators.

\footnotetext{
${ }^{7}$ For further discussion of these issues see Nolan and Whelan (2005)
} 
For the first set of items relating to relatively basic items such as food, clothes, heat and furniture respondents were asked if (1) the household possessed/availed the items (2) did not possess/avail of because they could not afford it or (3) did not possess/avail for other reason. A similar format was employed in relation to a range of consumer items such as a video, a stereo etc. A further set of 4 items concerned the absence of basic housing facilities. of these items, we assume that their absence is due to inability to afford them. An additional set of 5 items related to the quality of the dwelling and the neighbourhood environment and focused on problems relating to damp, light, noise, pollution or crime.

The questions described to this point concern households and household members. The final set of item we consider were addressed to individuals. The items related to, going without heating during the last 12 months through lack of money, having a morning, afternoon or evening out in the last fortnight for entertainment, a car.

An additional set of items relate to the health of the household reference person. We have extended our notion of material deprivation to incorporate health indicators because of the large body of evidence showing the relationship of more narrowly conceived deprivation to such outcomes. This contrasts with the much weaker associations observed in the case of factors such as social isolation that are often included under the notion of social exclusion. ${ }^{8}$ The specific questions were as follows:

\footnotetext{
${ }^{8}$ See Davey Smith et al (1994) and Gallie et al (2003).
} 
- Evaluation of general health. Five response options were offered. We considered respondents as having health problems when they answered from "fair" to "very bad”.

- If they suffered from any chronic illness or condition. A simple "yes" or "no" was offered to the respondents.

- If they have been limited in usual activities for at least the last 6 months because of a health problem. Three options were offered and those answering "yes very limited” and "limited” are considered as well as having health problems.

The final set of questions focused on a range of subjective economic pressures.

- The first identifies households that are incapable of coping with unanticipated expenses.

- The second relates to households incurring debts in relation to routine expenses.

- The third deals with arrears arising from mortgage, rent, hire purchase payments etc.

- The final item focuses on those households experiencing difficulty or great difficulty in making ends meet.

We will therefore make us of a total of forty-six indicators comprising the forty-two deprivation indicators and the four items relating to subjective economic pressures.

Our analysis refers to all persons in the EU-SILC Irish survey. Household characteristics have been allocated to each individual. Where more than one person answered a question, the response of the household reference person (HRP) has been allocated to each individual in the household. The HRP is the one responsible for the 
household accommodation. Where this responsibility was shared the oldest person was chosen.

In Table 1 we set out details of the full range of indicators, distinguishing those that the Irish CSO is required to provide to Eurostat as part of the common EU-SILC dataset from those that are specific to the Irish data set. 
Table 1: List of Common EU and Specific National Deprivation Indicators

\begin{tabular}{|c|c|c|}
\hline Deprivation Indicators & $\begin{array}{l}\text { Common EU } \\
\text { Set of } \\
\text { Indicators: } \\
\text { Provide in All } \\
\text { EU Member } \\
\text { States }\end{array}$ & $\begin{array}{l}\text { Additional } \\
\text { Indicators } \\
\text { Collected in } \\
\text { Ireland }\end{array}$ \\
\hline Cold - going without heating during a 12 month period through lack of money & & $\mathrm{X}$ \\
\hline \multicolumn{3}{|l|}{ Inability to afford: } \\
\hline Social Life - Not having a morning, afternoon or evening out once a fortnight & & $\mathrm{X}$ \\
\hline - Two pairs of strong shoes & & $\mathrm{X}$ \\
\hline - A roast joint (or its equivalent) once a week & & $\mathrm{X}$ \\
\hline - A meal with meat, chicken, fish (or vegetarian equivalent) every second day & $\mathrm{X}$ & \\
\hline - New rather than second-hand clothes & & $\mathrm{X}$ \\
\hline - A warm waterproof coat & & $\mathrm{X}$ \\
\hline - Keeping the home adequately warm & $\mathrm{X}$ & \\
\hline - Replacing worn out furniture & & $\mathrm{X}$ \\
\hline - Having family or friends for a drink or meal once a month & & $\mathrm{X}$ \\
\hline - Buying presents for family or friends at least once a year & & $\mathrm{X}$ \\
\hline \multicolumn{3}{|l|}{ Inability to afford: } \\
\hline - Paying for a week's annual holiday away from home & $\mathrm{X}$ & \\
\hline \multicolumn{3}{|l|}{ Enforced lack of: } \\
\hline - Fixed line telephone & $\mathrm{X}$ & \\
\hline - Computer & $\mathrm{X}$ & \\
\hline - Satellite Dish & & $\mathrm{X}$ \\
\hline - Video Recorder & & $\mathrm{X}$ \\
\hline - Stereo & & $\mathrm{X}$ \\
\hline - CD Player & & $x$ \\
\hline - Camcorder & & $\mathrm{X}$ \\
\hline - Clothes Dryer & & $\mathrm{X}$ \\
\hline - Dish washer & & $\mathrm{X}$ \\
\hline - Vacuum Cleaner & & $\mathrm{X}$ \\
\hline - Fridge with separate freezer section & & $\mathrm{X}$ \\
\hline - Deep Freeze & & $\mathrm{X}$ \\
\hline - Microwave & & $\mathrm{X}$ \\
\hline - Deep fat fryer & & $\mathrm{X}$ \\
\hline - Liquidiser & & $\mathrm{X}$ \\
\hline - Food processor & & $\mathrm{X}$ \\
\hline Private Car & $\mathrm{X}$ & \\
\hline - Washing Machine & $\mathrm{X}$ & \\
\hline Bath or shower & $\mathrm{X}$ & \\
\hline Toilet (internal) & $\mathrm{X}$ & \\
\hline Central Heating & & $\mathrm{X}$ \\
\hline Piped Hot water & & $\mathrm{x}$ \\
\hline \multicolumn{3}{|l|}{ Problems with Accommodation and the Environment: } \\
\hline $\begin{array}{l}\text { - Leaking roof, damp walls/ceilings/floors/foundations, rot in the doors window } \\
\text { frames or the floor }\end{array}$ & $\mathrm{X}$ & \\
\hline - Too dark or don't have enough light & $\mathrm{X}$ & \\
\hline - Pollution grime or other environmental problems caused by traffic or industry & $\mathrm{X}$ & \\
\hline - Crime or vandalism in the area & $\mathrm{X}$ & \\
\hline - Noise from neighbours or outside & $\mathrm{x}$ & \\
\hline -Assessment of Health & $\bar{X}$ & \\
\hline -Chronic Illness & $\mathrm{X}$ & \\
\hline -Mobility restriction & $\mathrm{X}$ & \\
\hline \multicolumn{3}{|l|}{ Subjective Economic Pressures } \\
\hline - Coping with unanticipated expenses & $\mathrm{X}$ & \\
\hline Arrears relating to mortgage, rent or hire purchase & $\mathrm{X}$ & \\
\hline $\begin{array}{l}\text { Debt to meet ordinary living expenses such as food, Christmas or back-to-school } \\
\text { expenses? }\end{array}$ & & $\mathrm{X}$ \\
\hline Degree of difficulty in making ends meet & $\mathrm{X}$ & \\
\hline
\end{tabular}




\section{Dimensions of Deprivation}

The first step in our analysis involves an investigation of the dimensionality of the forty-two deprivation items included in the first full wave of the Irish survey. Employing a factor analysis that permits the factors to be associated the following five relatively distinct life-style deprivation dimensions were identified. ${ }^{9}$ These comprise:

Economic strain - consisting of 11 items relating to food, clothing, furniture, debt and minimal participation in social life. ${ }^{10}$

Consumption deprivation - comprising 19 items focusing mainly on a range of consumer durables including a phone, PC, Video, CD, dish-washer etc.

Housing facilities - is a 4-item index comprising basic facilities such as bath, toilet etc.

Neighbourhood environment - is a 5-item index encompassing pollution, crime/vandalism, noise and deteriorating housing conditions.

Health status of the HRP. This dimension comprises 3 items relating to overall evaluation of health status, having a chronic illness or disability and restricted mobility.

Consistent poverty measures incorporating the 11-item economic strain index have been shown to differentiate sharply between respondents in terms of the range of deprivation dimensions identified above items and a set of indicators relating to the

\footnotetext{
${ }^{9}$ See Whelan et al (2006) for a detailed discussion of these findings

${ }^{10}$ Note that this index differs substantially from that incorporated in the Irish National AntiPoverty Strategy consistent poverty targets in that it includes number of items relating to participation in family and social life. The terminology has also been changed
} 
subjective experience of economic pressures. The index is thus confirmed to be a highly reliable and valid measure of such poverty. ${ }^{11}$

In conducting a comparable analysis for a set of items that will be available in the harmonized EU-SILC data set our options are a good deal more restricted. We finally settled on a set of 20 items and conducted a factor analysis based on this set. The available indicators include a good deal fewer items relating to consumer deprivation and somewhat fewer dealing with economic strain, than in Irish case. In light of this, we include three items relating to subjective economic pressures in the EU-SILC common economic strain index in the expectation that they might serve as proxies for such strain. Given the range of items available, it seemed unlikely that we will be able to establish empirically the distinction between the economic strain and consumption deprivation dimensions. As the factor analysis results set out in Table 2 reveal, this turns out to be the case. Four distinct dimensions emerge. The first, to which we will apply the label 'economic strain', involves a mixture of items that in the Irish analysis were divided between the economic strain and consumption deprivation dimensions, together with the three subjective economic pressures indicators. Items falling into the first category include being unable able to afford a meal with meat, fish or chicken and keeping the household adequately warm. The second category comprises the enforced absence of a car, a telephone, a PC and a holiday away from home once a year. The subjective pressure items include being unable to cope with unanticipated expenses, debt problems arising from ordinary living expenses, and arrears relating to mortgage, rent or hire purchase payments. The neighbourhood environment dimension and health status dimensions are identical to those identified in the Irish

\footnotetext{
${ }^{11}$ See Maître et al (2006)
} 
case. The housing dimension is slightly different it that it comprises three rather than four items and includes the item relating to a washing machine.

\begin{tabular}{|c|c|c|c|c|}
\hline \multicolumn{5}{|c|}{ Deprivation Dimensions } \\
\hline & Economic Strain & $\begin{array}{l}\text { Housing } \\
\text { Facilities }\end{array}$ & $\begin{array}{l}\text { Neighbourhood } \\
\text { Environment }\end{array}$ & Health \\
\hline Meals with meat, fish or chicken & .537 & & & \\
\hline Household Adequately Warm & .525 & & & \\
\hline Car & .545 & & & \\
\hline Telephone & .572 & & & \\
\hline PC & .626 & & & \\
\hline Holiday away from home & .660 & & & \\
\hline $\begin{array}{l}\text { Inability to cope with unexpected } \\
\text { expenses }\end{array}$ & .681 & & & \\
\hline $\begin{array}{l}\text { Debt problems arising from ordinary } \\
\text { expenses }\end{array}$ & .582 & & & \\
\hline $\begin{array}{l}\text { Arrears relating to mortgage, rent or } \\
\text { hire purchase }\end{array}$ & .619 & & & \\
\hline \multicolumn{5}{|l|}{ Bath or Shower } \\
\hline Hot water & & .836 & & \\
\hline Washing Machine & & .850 & & \\
\hline & & .360 & & \\
\hline Pollution & & & .721 & \\
\hline Crime, Violence, Vandalism & & & .683 & \\
\hline Noise & & & .728 & \\
\hline Leaking roof \& Damp & & & .396 & \\
\hline Rooms too Dark & & & .405 & \\
\hline & & & & \\
\hline & & & & \\
\hline & & & & \\
\hline Assessment of Health & & & & 0.842 \\
\hline Chronic Illness & & & & 0.869 \\
\hline Mobility restriction & & & & 0.889 \\
\hline
\end{tabular}

For our present purposes, it is the nine-item economic strain index that is crucial. From Table 2 we see that the items load on this factor in a relatively homogeneous manner with all nine values located in the range running from 0.50 to $0.68 .^{12}$ As shown in Table 3, the 9-item index has a highly satisfactory alpha coefficient of 0.79 that is slightly lower than for the corresponding 11-item Irish index, which has a value of 0.86 However, omitting the three subjective economic pressure items would reduce this value to 0.68 . The health and neighbourhood environment dimensions,

\footnotetext{
${ }^{12}$ Since weighting by level of deprivation has no significant effect on our results we operate with unweigthed indices
} 
which are common to both sets of analyses, have reliability coefficients of 0.82 and 0.58 respectively. The 3-item housing index from the deriving the common EU analysis has an alpha value of 0.56 , which is almost identical to that for the corresponding Irish specific index. The values for the housing and neighbourhood indices are lower than we would like but that it is not surprising given the small number of items involved.

\begin{tabular}{|l|l|}
\hline \multicolumn{2}{|l|}{ Table 3: Reliability Levels for Deprivation Dimensions } \\
\hline ECHP Common Dimensions & \\
\hline Economic Strain - 9 Item Scale & 0.787 \\
\hline Economic Strain - 6 Item Scale & 0.677 \\
\hline Housing - 3 Item scale & 0.560 \\
\hline Neighbourhood Environment - 5- scale & 0.578 \\
\hline Health - 3 Item Scale & 0.818 \\
\hline & \\
\hline Irish Specific Dimensions & \\
\hline Economic Strain - 11-Item Scale & 0.855 \\
\hline Consumption Deprivation - 18-item scale & 0.878 \\
\hline Housing - 4 -tem scale & 0.576 \\
\hline
\end{tabular}

The main difference arising from the separate analyses is that employing the full set of Irish items we can make a clear distinction between deprivation relating to rather basic items such as food, clothing, heat and social participation, which load on the economic strain dimension, and deprivation relating to consumer durables. The crucial question that remains is the extent to which the 9-item EU common index and the 11-item Irish specific indices of economic strain are measuring similar or different dimensions.

\section{Comparing EU Common and Irish Specific Measure of Consistent Poverty}

A definition of poverty in terms of exclusion from the life of one's society because of a lack of resources has been enshrined in the Irish National Anti-Poverty 
Strategy. In monitoring the evolution of poverty in Ireland over recent years extensive use has been made not only of household income but also of non-monetary indicators of deprivation, in order to obtain a more comprehensive picture of household living standards and command over resources. This approach is consistent with a trend towards increased emphasis on direct measurement of deprivation. ${ }^{13}$ Particular attention has been paid to those both falling below relative income thresholds and reporting basic deprivation of the kind captured by the Irish specific 11-item economic strain index. Those fulfilling both conditions are identified as experiencing generalised deprivation due to lack of resources. ${ }^{14}$

In order to implement the consistent poverty approach, it is necessary to choose a threshold for the economic strain index. A series of analyses by Maître et al (2006) indicated that the most appropriate cut off point for the 11-item Irish specific index was 2+ items. In order to facilitate comparison between the two indices we choose a cut off point off $3+$ for the 9-item EU-SILC common index that produces consistent poverty rates as close as possible to those produced by the 11 -item Irish specific index. The income threshold is set at $70 \%$ of household disposable equivalent income. From Table 4 we see that this approach produces a consistent poverty rate of 9.6\% for the Irish specific measure and 9.1\% for the EU common measure.

\footnotetext{
${ }^{13}$ Recent examples relating to Britain, New Zealand and the USA include McKay and Collard (2004), Perry (2002) and Short (2005) while Fõrster (2005) provides an example of a comparative European analysis.

${ }^{14}$ See Callan et al (1993), Nolan and Whelan, (1996) for early examples of this method and Maître et al (2006) for a revised approach using EU-SILC data.
} 
Table 4: Percentage Consistently Poor for EU Common and Irish Specific Measures

\begin{tabular}{|l|c|}
\hline & \% Consistently \\
\hline EU Common & 9.1 \\
\hline Irish Specific & 9.6 \\
\hline
\end{tabular}

While the two measures produce almost identical poverty rates, the question remains as to the extent to which they identify overlapping groups. From Table 5 we can see that only $2 \%$ of those not consistently poor on the EU common measure are so on the Irish specific measure. On the other hand, $20 \%$ of those consistently poor on the former are not so on the latter. Thus, there is a very considerable overlap but there remains a significant difference in the groups identified as consistently poor.

Table 5: Relationship between EU Common and Irish Specific Measures of Consistent Poverty at $70 \%$ of median Income

\begin{tabular}{|l|c|c|}
\hline & \multicolumn{2}{|c|}{ EU SILC Common 9 item } \\
\hline Irish Specific 11 Item & \multicolumn{2}{|c|}{ Consistently Poor } \\
\hline & No & Yes \\
\hline Consistently Poor & 97.7 & 20.1 \\
\hline & 2.3 & 79.9 \\
\hline No & 100 & 100.0 \\
\hline Yes & & \\
\hline Total & & \\
\hline
\end{tabular}

In order to explore the similarities and differences between the two measures, in Table 6 we set out the results of two logistic regressions displaying, for a range of socio economic characteristics of households and reference persons, the patterns of association with both measures of consistent poverty. For a number of such characteristics the odds ratios, which show the odds on being consistently poor for one rather than another category of an independent variable, are very similar for both indices. With regard to employment status, the only differences are that being selfemployed without employees has a marginally stronger effect in the Irish specific case 
while being a farmer, unemployed or an employee who has experienced unemployment in the past twelve months have slightly greater impact for the EU common measure. However, overall the similarities are a great deal more striking than the differences. Thus, for illness and disability the odds ratio in both cases is close to 9:1, for being in education 10:1 and for home duties 5:1. The similarities extend to the impact of urban location. In both cases the odds ratio for primary education is $4: 1$ and for separation/divorce is close to 3:1. Lone parenthood and having more than two children have a marginally greater impact on the EU common measure.

Two factors distinguish the measures. The first is that being consistently poor on the EU common index is much more strongly associated with being in the younger age groups than is the case for the Irish specific measure. Thus, in the comparison involving those in households where the reference person is aged thirty or less compared to those where s/he is aged $65+$ the odds ratio is $4: 1$ for the EU common measure compared to $1.5: 1$ for the Irish specific measure. The results for the comparison involving those aged 30-49 are almost identical. For those aged 50-64 the respective odds ratios are 2.3:1 and 1.2:1. The other major differentiating factor is household tenure. Being a private tenant has a marginally stronger association with the EU common measure. However, it is public sector tenancy that is the crucial differentiating factor. In reference to home owners the odds ratio for residents in such households is 6:1 for the EU common measure compared to less than $4: 1$ in the Irish specific case. 


\begin{tabular}{|c|c|c|c|c|}
\hline & \multicolumn{2}{|c|}{ EU Common } & \multicolumn{2}{|c|}{ Irish Specific } \\
\hline & $\operatorname{Exp}(\mathrm{B})$ & Sig. & $\operatorname{Exp}(B)$ & Sig. \\
\hline \multicolumn{5}{|l|}{ Employment Status } \\
\hline Self-employed with employees & 0.394 & $*$ & 0.353 & n.s. \\
\hline Self-employed without employees & 1.325 & $* *$ & 2.188 & $* * *$ \\
\hline Farmer & 0.520 & $*$ & 0.868 & n.s \\
\hline $\begin{array}{l}\text { Employee - unemployed in previous } 12 \\
\text { months }\end{array}$ & 4.138 & $* * *$ & 2.137 & $* * *$ \\
\hline Ill/Disabled & 8.613 & $* * *$ & 8.523 & \\
\hline Unemployed & 8.941 & $* * *$ & 7.453 & $* * *$ \\
\hline In Education & 9.527 & $* * *$ & 10.159 & $* * *$ \\
\hline Home-Duties & 5.064 & $* * *$ & 4.830 & $* * *$ \\
\hline Retired & 2.415 & $* * *$ & 1.923 & $* * *$ \\
\hline \multicolumn{5}{|l|}{ Marital Status } \\
\hline Single & 1.638 & $* * *$ & 1.761 & $* * *$ \\
\hline Widowed & 1.005 & n.s. & 0.834 & n.s. \\
\hline Separate/Divorced & 2.809 & $* * *$ & 3.045 & $* * *$ \\
\hline Number of Children $>2$ & 1.258 & $*$ & 1.165 & n.s \\
\hline Lone Parent & 2.217 & $*$ & 1.568 & $* * *$ \\
\hline \multicolumn{5}{|l|}{ Age Group } \\
\hline Under30 & 4.189 & $* * *$ & 1.533 & $*$ \\
\hline $30-49$ & 4.008 & $* * *$ & 1.678 & $* * *$ \\
\hline $50-64$ & 2.256 & $* * *$ & 1.159 & n.s \\
\hline \multicolumn{5}{|l|}{ Education } \\
\hline Primary & 4.174 & $* * *$ & 4.075 & $* * *$ \\
\hline Lower Secondary & 2.337 & $* * *$ & 2.680 & $* * *$ \\
\hline Urban Location & 0,802 & n.s. & 0.716 & $* *$. \\
\hline \multicolumn{5}{|l|}{ Tenure } \\
\hline Private Tenant & 1.748 & $* * *$ & 1.578 & $* * *$ \\
\hline Local Authority Tenant & 6.095 & $* * *$ & 3.893 & $* * *$ \\
\hline Nagelkerke $\mathrm{R}^{2}$ & 0.421 & & 0.344 & \\
\hline Chi Squared & 2.981 .7 & & $2,417.2$ & \\
\hline Degrees of Freedom & 22 & & 22 & \\
\hline
\end{tabular}


In order to bring out the consequences of these differences for the composition of the consistently poor groups, we construct a typology based on cross classifying the two consistent poverty measures. In Table 7 we break down age groups and housing tenure composition by this typology. Focusing on age f, we see that $67 \%$ of those who are poor on both measures are in households where the household reference is aged less than fifty, $12 \%$ are under thirty and $7 \%$ are aged sixty-five or over. The distribution for those poor on the EU common measures is very similar. However, the picture is quite different for those poor on the Irish specific measure only with $32 \%$ being aged sixty-five or over and only $5 \%$ being aged thirty or under. In relation to housing tenure, we see that almost $40 \%$ of those poor on both measures are home owners, $14 \%$ are private sector tenants and $45 \%$ are public sector tenants. This distribution is again almost exactly mirrored for those poor on the EU common measure only. For those poor on the Irish specific measure only the situation is quite different with $77 \%$ of this group being homeowners and only $14 \%$ being public sector tenants. Finally, almost $90 \%$ of those poor on neither measure are home owners. The Irish specific measure captures older home owning respondents who are not picked up by the EU general measure. ${ }^{15}$

\footnotetext{
${ }^{15}$ A multinomial regression involving these categories available from the authors confirms these findings.
} 


\begin{tabular}{|l|c|c|c|c|}
\hline \multicolumn{5}{|l|}{$\begin{array}{l}\text { Table 7: Age Group and Housing Tenure Composition by the EU Common and Irish } \\
\text { Consistent Poverty Typology }\end{array}$} \\
\hline & Poor on Both & $\begin{array}{l}\text { Poor on Irish } \\
\text { Measure Only }\end{array}$ & $\begin{array}{l}\text { Poor on EU } \\
\text { Measure Only }\end{array}$ & $\begin{array}{l}\text { Poor on } \\
\text { Neither }\end{array}$ \\
\hline & $\%$ & $\%$ & $\%$ & $\%$ \\
\hline Age Group & & & & 4.9 \\
\hline$<30$ & 12.2 & 4.7 & 16.0 & 47.4 \\
\hline $30-49$ & 55.2 & 31.2 & 53.4 & 32.7 \\
\hline $50-64$ & 25.6 & 32.2 & 22.9 & 14.9 \\
\hline $65+$ & 7.1 & 31.9 & 7.6 & \\
\hline & & & & 87.6 \\
\hline Housing Tenure & & & & 7.7 \\
\hline Owner & 40.4 & 76.6 & 37.4 & 4.7 \\
\hline Private Tenant & 14.3 & 9.5 & 15,3 & \\
\hline $\begin{array}{l}\text { Public Sector } \\
\text { Tenant }\end{array}$ & 45.3 & 13.9 & 47.3 & \\
\hline
\end{tabular}

\section{Economic Vulnerability}

In this section we broaden our focus to consider economic vulnerability. Following Chambers (1989:1), we define vulnerability as not necessarily involving current deprivation either in income or other terms but rather insecurity and exposure to risk and shock. One objective of developing measures of vulnerability is that they should serve as point in time proxies for risk of exposure to persistent disadvantage. This objective is combined with a concern to go beyond measures based on single indicators. The IMF (2003), the UN (2003) and the World Bank (2000) have developed a range of approaches to measuring vulnerability at the macro level. Consistent with the approach developed here, the World Bank sees vulnerability as reflecting both the risk of experiencing an episode of poverty over time but also a heightened probability of being exposed to a range of risks.

Here following Whelan and Maître (2005 a \& b), we implement an approach to the measurement of vulnerability at the micro level through the use of latent class 
analysis. The basic idea underlying such analysis is the associations between a set of categorical variables, regarded as indicators of an unobserved typology, are accounted for by membership of a small number of underlying latent classes. ${ }^{16}$

Our focus initially is on three indicators - household income, economic strain and reporting that one's household experiences difficulty in making ends meet. In order to provide us with sufficient degrees of freedom our income poverty variable has four categories distinguishing between those below 50\% median income, between 50-60\%, between $60 \%$ to $70 \%$ and above $70 \%$. Our analysis is thus based on the distribution of frequencies in a 4x2x2 table. For income we report the conditional probabilities of being below each of the three median income lines and for economic strain the risk of an enforced lack of three or more items on the 9-item EU common index. The economic stress variable distinguishes those households that have difficulty or great difficulty in making ends meet. ${ }^{17}$ Our objective is to identify a group who are vulnerable to economic exclusion in being distinctive in their risk of falling below a critical resource level, being exposed to rather basic life-style deprivation and in their level of subjective economic stress.

In Table 8 we show the results of fitting such a model. The goodness of fit indicators include the percentage of cases misclassified and the reduction in the deviance level compared to the independence model. The model misclassifies less than $1 \%$ of cases. The $G^{2}$ measure of goodness of fit returns a value of 24.1 with 4 degrees of freedom

\footnotetext{
${ }^{16}$ See Lazarsfeld and Henry, 1968 and more recently Magdison and Vermunt (2004) and McCutcheon, and Mills (1998) for discussion of latent class models. Recent applications to the analysis of social exclusion include Moisio (2004) and Dewilde (2004), Whelan and Maître (2004 \& 2005).

${ }^{17}$ We use the label economic stress for this variable rather than economic strain as in earlier work because Eurostat has taken to using the latter term for something close to the basic deprivation index employed in earlier Irish work on consistent poverty.
} 
that reduces the value of the benchmark independence model by $99.4 \%$. The model identifies one in five of the population as being economically vulnerable. At all three income poverty lines the vulnerable are significantly more likely to be below the relevant threshold. At the $50 \%$ line the respective percentages are $31 \%$ and $6 \%$ and these rise to $68 \%$ and $19 \%$ at $70 \%$ of median income. The contrast between economic vulnerability and income poverty is clearly illustrated by these results. At the $60 \%$ line, where the number income poor is almost identical to that economically vulnerable, just over one in two of those below the income threshold are vulnerable. Furthermore, there is no tendency for the association between income poverty and vulnerability to strengthen as the income threshold is made more stringent. In fact, the opposite is the case with the odds ratio declining from $9.1: 1$ at the $70 \%$ line to $7.3: 1$ at the $60 \%$ line and finally to $6.6: 1$ at the $50 \%$ line.

Table 8: Latent Class EU Common Analysis of Economic Vulnerability

\begin{tabular}{|c|c|c|}
\hline Vulnerable Class Size & \multicolumn{2}{|c|}{19.6} \\
\hline $\mathrm{G}^{2}$ & \multicolumn{2}{|c|}{24.1} \\
\hline Degrees of freedom & \multicolumn{2}{|c|}{$99.4 \%$} \\
\hline $\mathrm{r}^{2}$ of independence model & \multicolumn{2}{|c|}{0.9} \\
\hline$\%$ of case misclassified & Non-Vulnerable \\
\hline Conditional Probabilities & 0.063 & Vulnerable \\
\hline Income & 0.120 & 0.308 \\
\hline$<50 \%$ of median & 0.190 & 0.498 \\
\hline$<60 \%$ of median & 0.025 & 0.680 \\
\hline$<70 \%$ of median & & 0.656 \\
\hline & 0.111 & 0.821 \\
\hline Economic Strain (3+) & & \\
\hline Dificulty in making ends meet & & \\
\hline
\end{tabular}

The economically vulnerable are also sharply differentiated in terms of their exposure to subjective economic stress with the respective figures being $82 \%$ and $11 \%$. However, while these disparities are substantial, the primary factor differentiating the latent classes is their risk of experiencing an enforced lack three or more items on the 
9-item the economic strain index. While $66 \%$ of the vulnerable group fall into this category this is true of only $3 \%$ of the non-vulnerable.

Substituting the 11-item Irish economic strain measure with a threshold of $2+$ into this analysis produces a remarkably similar set of results. It too identifies one-fifth of the population as vulnerable. The pattern of differentiation between vulnerable and nonvulnerable is also strikingly similar with the only notable difference being that the probability of being above the economic strain threshold is even lower for the nonvulnerable cluster in the Irish specific case with the relevant figure being $1.3 \%$ rather than $2.5 \%$.

The latent class analyses, involving the alternative economic strain indices, identify identical numbers of the population as economically vulnerable and produce remarkably similar multidimensional profiles. However, as in the case of consistent poverty, the question remains as to whether the different approaches are identifying the same or different groups. From Table 9 we can see that $4 \%$ of those nonvulnerable in the EU-SILC common case are classified as vulnerable in the Irish case and $10 \%$ of the vulnerable are placed in the non-vulnerable cluster. In other words $90 \%$ of those found to be economically vulnerable by the EU common analysis are also vulnerable using the Irish specific measure. 


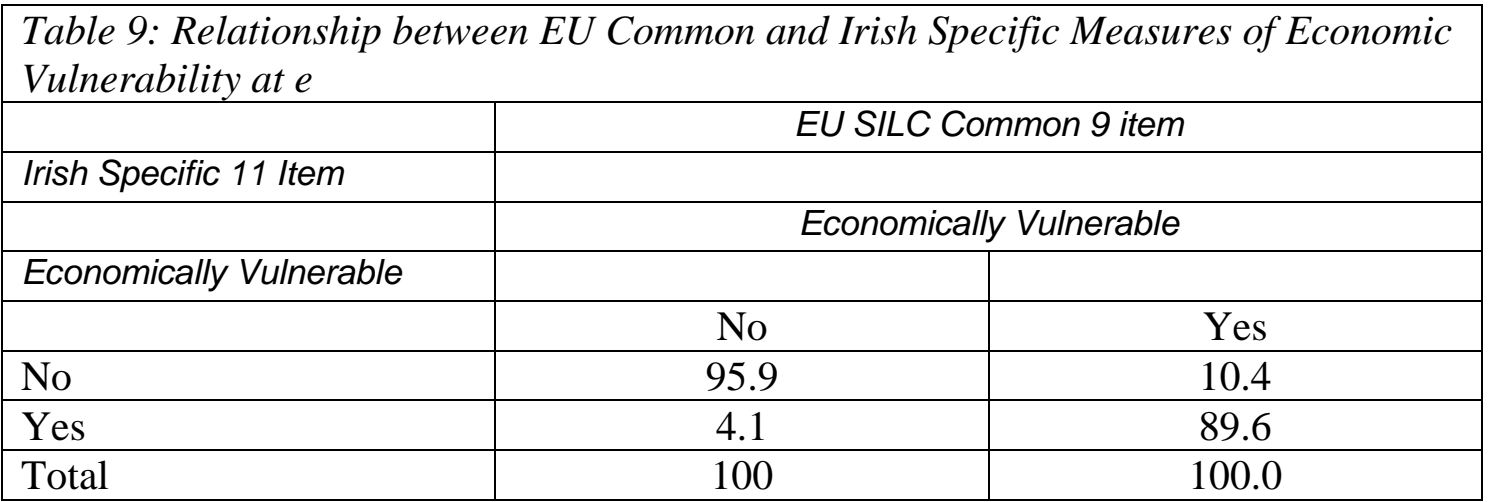

In Table 10 we extend our analysis to provide a comparison of the socio-economic factors associated with membership of the respective vulnerability clusters. In this case the degree of similarity is even more striking than for consistent poverty. Some very modest differences are apparent in relation to employment status, however, what is really striking is the similarity of odds ratios across equations. This pattern is maintained across the remaining independent variables with the only difference of any magnitude being observed for age. Even here the differences are more modest than in the case of consistent poverty. Thus, for the comparison between those aged thirty or less and those aged sixty-five or more the odds ratio rises from $1.6: 1$ in the Irish specific case to 3.1:1 for the EU common. Similar but more modest differences exist for the remaining age comparison. In composition terms, this results in a situation whereby $20 \%$ of those vulnerable on the EU common measure only are in households where the reference person is aged less than thirty and only $3 \%$ in ones where s/he is aged sixty five or over. The corresponding figures for the Irish specific measure are $7 \%$ and $19 \%{ }^{18}$

\footnotetext{
${ }^{18}$ Once again a multinomial regression analysis, which is available from the authors, confirms these findings.
} 


\begin{tabular}{|c|c|c|c|c|}
\hline & \multicolumn{2}{|c|}{ EU Common } & \multicolumn{2}{|c|}{ Irish Specific } \\
\hline & $\operatorname{Exp}(\mathrm{B})$ & Sig. & $\operatorname{Exp}(\mathrm{B})$ & Sig. \\
\hline \multicolumn{5}{|l|}{ Employment Status } \\
\hline Self-employed with employees & 0.243 & $* * *$ & 0.576 & $* *$ \\
\hline Self-employed without employees & 1.432 & $*$. & 1.550 & $* *$. \\
\hline Farmer & 2.232 & $* * *$ & 2.196 & $* * *$ \\
\hline $\begin{array}{l}\text { Employee - unemployed in previous } 12 \\
\text { months }\end{array}$ & 2.192 & $* * *$ & 1.686 & $* * *$ \\
\hline Ill/Disabled & 6.875 & $* * *$ & 6.172 & $* * *$ \\
\hline Unemployed & 4.903 & $* * *$ & 4.838 & $* * *$ \\
\hline In Education & 4.371 & $* * *$ & 4.171 & $* * *$ \\
\hline Home-Duties & 3.352 & $* * *$ & 2.752 & $* * *$ \\
\hline Retired & 2.357 & $* * *$ & 1.759 & $* * *$ \\
\hline Marital Status & & & & $* * *$ \\
\hline Single & 1.451 & $* * *$ & 1.327 & $* * *$ \\
\hline Widowed & 1.130 & $* * *$ & 1.298 & $* *$ \\
\hline Separate/Divorced & 2.277 & $* * *$ & 2.354 & $* * *$ \\
\hline Number of Children $>2$ & 2.040 & $* * *$ & 1.945 & $* * *$ \\
\hline Lone Parent & 2.957 & $* * *$ & 2.926 & $* * *$ \\
\hline Age Group & & & & $* *$ \\
\hline Under30 & 3.052 & $* * *$ & 1.644 & $* *$ \\
\hline $30-49$ & 3.071 & $* * *$ & 2.025 & $* * *$ \\
\hline $50-64$ & 1.864 & $* * *$ & 1.261 & $* * *$ \\
\hline \multicolumn{5}{|l|}{ Education } \\
\hline Primary & 4.088 & $* * *$ & 3.424 & $* * *$ \\
\hline Lower Secondary & 2.615 & $* * *$ & 2.262 & $* * *$ \\
\hline Rural Location & 0.800 & $* * *$ & 0.927 & n.s. \\
\hline \multicolumn{5}{|l|}{ Tenure } \\
\hline Private Tenant & 2.582 & $* * *$ & 2.316 & $* * *$ \\
\hline Local Authority Tenant & 4.134 & $* * *$ & 3.393 & $* * . *$ \\
\hline Nagelkerke $\mathrm{R}^{2}$ & 0.356 & & 0.311 & \\
\hline Chi Square & $3,454.9$ & & $3,045.5$ & \\
\hline Degrees of Freedom & 22 & & 22 & \\
\hline
\end{tabular}


The different measures of economic strain lead to almost identical conclusions regarding levels of economic exclusion and the pattern of multidimensional differentiation. However, what is even more striking is that, with key exceptions, they produce broadly similar conclusions regarding the socio-economic profile of the vulnerable.

\section{Multiple Deprivation Profiles}

The economic vulnerability approach takes us beyond the unidimensional perspective associated with a focus on the relative income approach. However, it still involves a rather more restricted view of deprivation than that typically associated with the notions of "multiple deprivation". In this section we seek to take advantage of the range of life-style deprivation items available in the Irish component of EU-SILC to develop an understanding of the consequences of economic vulnerability, as measured using the EU-SILC common items, for more broadly conceived patterns of deprivation.

In order to pursue this analysis, we distinguish between those who are economically vulnerable and consistently poor, those vulnerable and those who are neither. Since the consistently poor are a sub-set of the economically vulnerable, for convenience we will refer to the first category as the consistently poor and the second as the economically vulnerable. In Table 11 we then consider the patterns of differentiation across the categories of these typologies for the five life-style deprivation dimensions identified in the Irish survey. In both cases we see that deprivation increases for each dimension as one moves from non-vulnerable group to the vulnerable and then to the consistently poor. With the exception of the health dimension, the vulnerable group occupies a position close to half way between the non-vulnerable and the consistently 


\begin{tabular}{|c|c|c|c|c|c|}
\hline \multicolumn{6}{|c|}{$\begin{array}{l}\text { Table 11: Variation Across Irish Specific Deprivation Dimensions by Consistent } \\
\text { Poverty and Economic Vulnerability at both The Irish and EU Common Level }\end{array}$} \\
\hline & $\begin{array}{c}\text { Economic } \\
\text { Strain }\end{array}$ & $\begin{array}{c}\text { Consumptio } \\
n \\
\text { Deprivation }\end{array}$ & $\begin{array}{c}\text { Housing } \\
\text { Deprivation }\end{array}$ & $\begin{array}{l}\text { Neighbourhoo } \\
\text { d Deprivation }\end{array}$ & Health \\
\hline & Mean & Mean & Mean & Mean & Mean \\
\hline \multicolumn{6}{|l|}{$\begin{array}{l}\text { EU Common } \\
\text { Level }\end{array}$} \\
\hline Not Vulnerable & 0.21 & 0.71 & 0.08 & 0.45 & 0.55 \\
\hline $\begin{array}{l}\text { Vulnerable \& } \\
\text { Not Poor }\end{array}$ & 1.87 & 3.49 & 0.18 & 0.87 & 1.02 \\
\hline $\begin{array}{l}\text { Vulnerable \& } \\
\text { Poor }\end{array}$ & 3.81 & 6.78 & 0.41 & 1.20 & 1.23 \\
\hline $\begin{array}{l}\text { Ratio of } \\
\text { Vulnerable \& } \\
\text { poor to Non- } \\
\text { Vulnerable }\end{array}$ & 18.1 & 9.5 & 5.1 & 2.7 & 2.2 \\
\hline $\mathrm{Eta}^{2}$ & 0.423 & 0.431 & 0.045 & 0.060 & 0.045 \\
\hline \multicolumn{6}{|l|}{ Irish Specific } \\
\hline Not Vulnerable & 0.10 & 0.71 & 0.08 & 0.45 & 0.54 \\
\hline $\begin{array}{l}\text { Vulnerable \& } \\
\text { Not Poor }\end{array}$ & 1.98 & 3.45 & 0.20 & 0.87 & 1.02 \\
\hline $\begin{array}{l}\text { Vulnerable \& } \\
\text { Poor }\end{array}$ & 4.29 & 6.32 & 0.40 & 1.18 & 1.27 \\
\hline $\begin{array}{l}\text { Ratio of } \\
\text { Vulnerable \& } \\
\text { poor to Non- } \\
\text { Vulnerable }\end{array}$ & 42.9 & 8.9 & 5.0 & 2.6 & 2.4 \\
\hline $\mathrm{Eta}^{2}$ & 0.585 & 0.388 & 0.047 & 0.061 & 0.052 \\
\hline
\end{tabular}

poor. In the case of health the vulnerable are closer to the consistently poor. For both the EU common and the Irish specific profiles the extent of variation across the typology declines as one moves from the economic strain to consumption deprivation and then to housing, neighbourhood environment and health status. The disparity 
ratios summarising the scale of the disadvantage experienced by the consistently poor in comparison with the non-vulnerable are respectively 18:1, 10:1, 5:1, 3:1 and 2:1.

Turning our attention to how the EU common typology fares in comparison with its Irish specific counterpart, we find that both the observed disparities and the proportions of variance explained are pretty well identical. In the case of consumer deprivation, the EU common typology produces a slightly higher disparity ratio and accounts for a slightly higher proportion of the variance. However, the major contrast relates to economic strain. The level for the non-vulnerable in the Irish specific typology is $50 \%$ that for their EU common counterparts while for the consistently poor it is $10 \%$ higher. As a consequence, the disparity ratio relating to the comparison between these two groups rise from 18:1 in the latter case to 43:1 in the former. Similarly, the proportion of variance explained rises from $42 \%$ to $59 \%$.

Only in relation to the capacity to differentiate between those experiencing the kind of extreme deprivation captured in the items that make up the Irish specific economic strain index does it fare less well. However, this difference is of some importance since ability to discriminate in relation to such deprivation is of fundamental importance in a poverty measure and the Irish specific index is therefore clearly superior. However, what is striking is not that the more restricted, and less theoretically grounded set of EU items, performs less well but rather that they provide the basis for identifying groups who are so sharply differentiated in relation to a range of life-style dimensions including the Irish specific economic strain index. 


\section{Conclusions}

In this paper we have considered the consequences for the measurement of material deprivation, consistent poverty and economic strain of the shift from the ECHP data set to the EU-SILC instrument. By taking advantage of the availability of the much wider set of indicators available in the Irish version of EU-SILC, it has been possible to evaluate the more restricted EU-wide indices by placing them in the context of measures constructed on a theoretically informed basis and validated in relation to a range of external indicators.

A comparison of consistent poverty measures based on EU common and Irish specific measures of economic strain revealed a substantial overlap with eight out of ten of those consistently poor on the former also being poor on the latter. The major difference between the measures is that the EU common index is significantly more likely to identify younger individuals and correspondingly less likely to identify homeowners. In each case one fifth of the population was identified as economically vulnerable with the pattern of differentiation between the vulnerable and nonvulnerable being strikingly similar. The overlap between the measures is even greater than in the case of consistent poverty and the socio-economic profiles of the groups identified are remarkably similar.

By creating typologies that combined information on consistent poverty and economic vulnerability, we were able to show that using the EU wide measures it is possible to identify clusters of individual who are differentiated across a wide range of deprivation dimensions. They also provide us with an understanding of the socio- 
economic factors associated with such differentiation that departs in only modest respects from that derived from the more comprehensive set of Irish specific indicators. Our analysis holds out the prospect that the harmonised EU-SILC data set will allow us to continue to pursue important aspects of the research agenda relating to multi-dimensional deprivation developed on the basis of the ECHP. Further studies comparing EU common and country specific approaches have the potential to deepen our understanding of how the set of deprivation measures available in EU-SILC might best be revised at a later stage.

\section{References}

Breen, R and Moisio, P., 'Overestimated Poverty Mobility: Poverty Dynamics Corrected for Measurement Error', Journal of Economic Inequality, 2004, 2.3:171191. 
Callan, T., Nolan, B., Whelan, C. T. (1993), “Resources, Deprivation and the Measurement of Poverty”, Journal of Social Policy, 22, 2:141-172.

Central Statistics Office (2005), EU Survey on Income and Living Conditions (EUSILC); First Results 2003, Statistical Release 24 January, SO: Dublin/Cork

Chambers, R. (1989), 'Vulnerabilty: How the Poor Cope, Editorial IDS Bulletin, 20:2

Davey Smith, Blane, D. and Bartley, M. (1994), 'Explanations for Socio-economic Differentials in mortality;, European Journal of Public Health, 4:131-144.

Dewilde, D. (2004),'The Multidimensional Measurement of Poverty in Belgium and Britain: A Categorical Approach, Journal of Social Indicators, 68, 3, 331 - 369

Eurostat (2005a), 'Income Poverty and Social Exclusion in the EU25' Statistics in Focus 03/2005, A.-C. Guio

Eurostat (2005b), 'Material Deprivation in the EU’ Statistics in Focus 05/2005, A.-C. Guio.

Förster, M, F. (2005), 'The European Social space Revisited: Comparing Povery in the Enlarged European Union', Journal of Comparative Policy Analysis, 7,1:29-48.

Gallie, D., Paugam, S. and Jacobs, S. 920030, ‘Unempolyment, Poverty and Social Isolation', European Societies, 5,1:1-31. 
International Monetary Fund (2003), Vulnerability Indicators: A Factsheet, www.imf.org/external/np/exr/facts/vul.html

Lazarsfeld, P.F., \& Henry, N.W.(1968), Latent Structure Analysis. Boston: Houghton Mifflin

Magidson, J. and Vermunt, J. (2004), 'Latent Class Models’, in D. Kaplan (ed), Hanbook of Quantitative Methodology, London: Sage

Mc Kay, S. and Collard, S. (2003), Developing Deprivation Questions for the Family Resources Survey, Department for Work and Pensions Working paper Numner13. Corporate Document Series

Mc Cutcheon, A. and Mills, A. (1998), 'Categorical Data Analysis; Log-Linear and Latent Class Models, in Scarborough, E. Tannenbauum, E., Research Strategies in the Social Sciences, Oxford, Oxford University Press

Moisio P. (2004), ‘ A Latent Class Application to the Multidimensional Measurement of Poverty', Quantity and Quality-International Journal of Methodology

Muffels, R. \& Fouarge, D.,' The Role of European Welfare States in Explaining Resources Deprivation’. Social Indicators Research, (2004) 68: 299-330

Nolan, B. and Whelan, C. T. (1996), 'Resources, Deprivation and Poverty', Oxford and New York: Oxford University Press, Clarendon Press. 
Nolan, B. and C. T. Whelan, (2005). “On the Multidimensionality of Poverty and Social Exclusion”, paper presented at European Consortium for Sociological Research Conference on Comparative European Studies: Assessing Ten Years of Sociological Research 1995-2005. Paris: 25/26 November.

Perry, B. (2002), 'The Mismatch Between Income Measures and Direct Outcome Measures of Poverty’, Social Policy Journal of New Zealand, 19:101-127

Short, K. S. (2005), 'Material and Financial Hardship and Income-based Poverty Measures in the USA', Journal of Social Policy, 34,1:21-38.

Tsakloglou, P. and Papadopoulous, F. (2002) ‘Aggregate level and determining factors of social exclusion in twelve European countries', Journal of European Social Policy, 12 (3): 211_ 25.

United Nations (2003), Report on the World Social Situation: Social Vulnerability: Sources and Challenges, New York: United Nations Department of Economic and Social Affairs.

Whelan, C.T., Layte, R. \& Maître, B. (2004), "Understanding the Mismatch Between Income Poverty and Deprivation: A Dynamic Comparative Analysis", European Sociological Review, 20, 4: 287-30 
Whelan, C.T., Maître, B. (2005a), “Economic Vulnerability, Multi-dimensional Deprivation and Social Cohesion in an Enlarged European Union”, International Journal of Comparative Sociology, 46, 3:215-239.

Whelan, C.T, Maître, B. (2005b), "Vulnerability and Multiple Deprivation Perspectives on Economic Exclusion in Europe: A Latent Class Analysis”, European Societies, 7,3:423-450.

Whelan, C. T., Maître, B. and Nolan, B. (2006), 'Measuring Consistent Poverty in Ireland, with EU SILC Data', Dublin: Economic and Social Research Institute, Working Paper No. 165.

Whelan, C. T. and Maître, B (2006), 'Levels and Patterns of Material Deprivation in Ireland: After the 'Celtic Tiger', Dublin: Economic and Social Research Institute, Working Paper No. 171.

World Bank (2000), World Development Report 2000-01: Attacking Poverty, New York: Oxford University Press. 